\section{Baculovirus-Transfer Vector for Eukaryotic Expression and Immuno- affinity Purification of Gal4-Fusion Proteins}

\section{BioTechniques 26:808-814 (May 1999)}

Artificial targeting of proteins to a promoter by fusion to the heterologous DNA binding domain (DBD) of yeast transcription factor Gal4 has been used in a large array of biological assays including yeast two hybrid assays. Vectors for transient expression of Gal4DBD fusion proteins in mammalian cells have been widely used in dissecting and mapping the activation or repression domains of transcription factors in vivo $(8,11)$. Highly purified Gal4 fusion proteins have been used in cell-free systems for investigating transcriptional regulation mechanisms or the chromatin-remodeling effects of regulatory domains in vitro (4). In addition, purified Gal4 fusion proteins can be immobilized onto a sensor chip bearing the Gal4-DNA recognition element to detect interactions with molecules in the liquid phase flowing over the chip using surface plasmon resonance (SPR) spectroscopy (5).

Vectors described previously for purification of Gal4-DBD fusion proteins are restricted to the prokaryotic Escherichia coli expression system, and purification requires either several rounds of conventional chromatography (7) or gradually renaturing proteins solubilized from $E$. coli inclusion bodies $(9,10)$. In addition to the lack of appropriate protein folding and posttranslational modifications, the sizes of proteins fused with Gal4 are also limited by the E. coli expression system. Frequently, large proteins are either not efficiently expressed or form insoluble aggregates that cannot readily be dissolved. Here, we describe a novel baculovirus-transfer vector allowing expression of N-terminal FLAG ${ }^{\circledR}$ epitope (a highly hydrophilic 8 amino acid [aa] peptide with sequence DYKDDDDK) tagged Gal4-DBD fusion proteins in insect cells. Using this vector and the single-step immunoaffinity purification procedure described below, we have purified a Gal4-DBD fusion protein (more than $110 \mathrm{kDa}$ in size) to near homogeneity from the nuclear extracts of infected Sf9 insect cells. The expression and purification of Gal4-fusion proteins can be easily monitored by immunoblotting analyses with commercially available antibodies against the Gal4-DBD and the FLAG epitope. Furthermore, the immunoaffinity-purified Gal4 fusion protein shows Gal4specific DNA binding activity as judged by electrophoretic mobility shift assays (EMSA).

The Drosophila Groucho (Gro) protein is a global co-repressor that plays multiple roles in development, and Gro itself does not appear to interact directly with DNA (2). In an effort to illuminate the mechanism of transcriptional repression by Gro, we attempted to purify a Gal4-Gro fusion protein using a baculovirus-expression system and to reconstitute the Gro-mediated repression in vitro in conjunction with Gal4targeted promoters. To achieve this goal, we have constructed a baculovirus transfer vector pVLf:Gal4-Gro (depicted in Figure 1) for generating a recombinant baculovirus expressing FLAGtagged, Gal4-Gro fusion protein in insect cells. To construct pVLf:Gal4Gro, we first produced a DNA fragment encoding the FLAG-tagged, Gal4-Gro fusion using $P f u$ DNA Polymerase

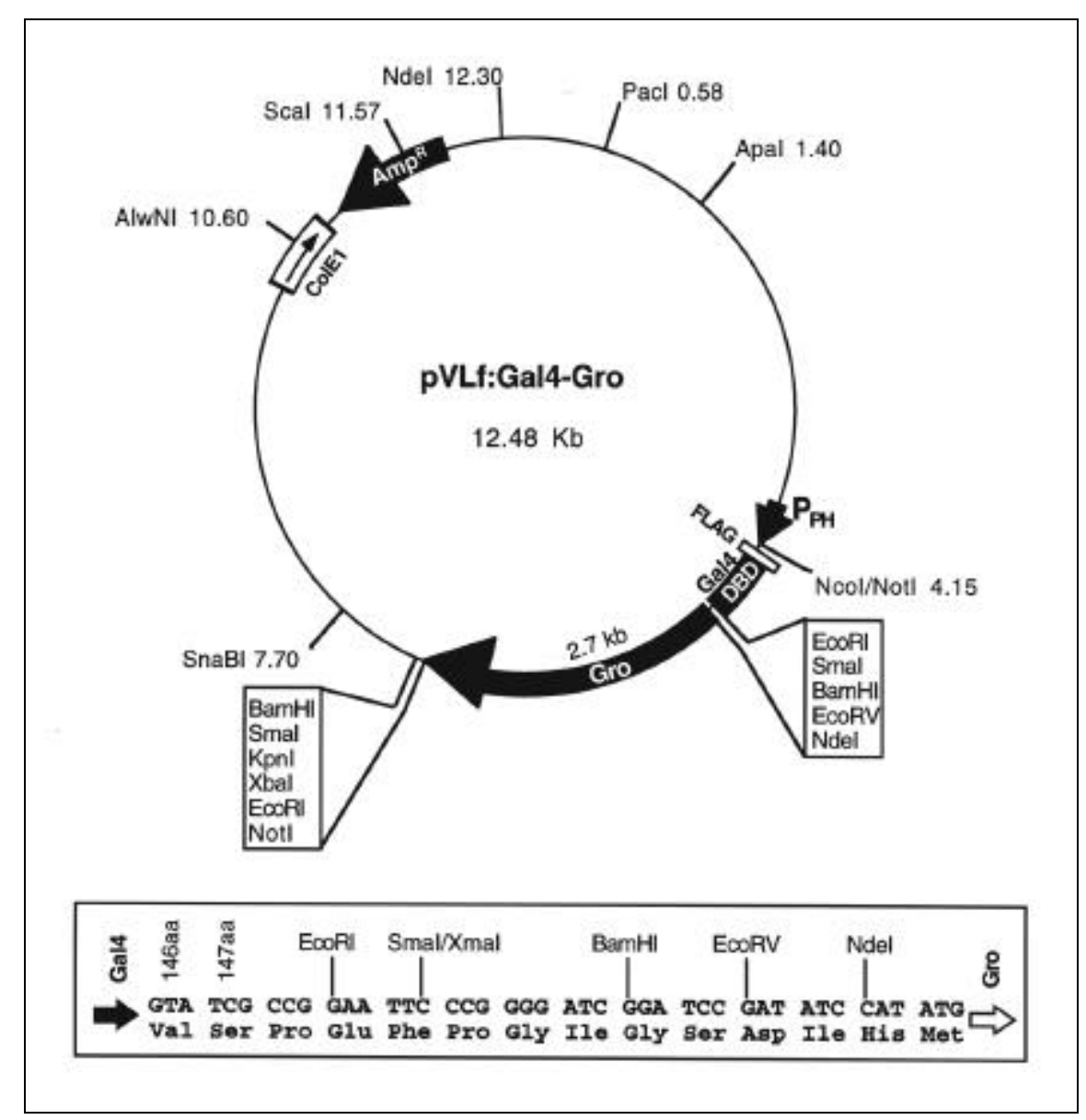

Figure 1. Restriction map and cloning sites of pVLf:Gal4-Gro. The pVLf:Gal4-Gro vector is constructed by inserting a PCR-generated DNA fragment encoding the FLAG-tagged Gal4 (residue 1-147)Gro fusion protein into the NotI site of baculovirus transfer vector pVL1392 (see text for details). The initiation ATG codon of the FLAG epitope is in a Kozak consensus context 5'-GCCATGG-3'. The resulting Gal4 fusion has a predicted N-terminal aa sequence MDYKDDDDKMKLL (the first 4 aa of Gal4 are underlined). $\mathrm{P}_{\mathrm{PH}}$ indicates the polyhedrin promoter derived from Autographa californica nucleopolyhedrovirus (AcNPV). Partial sequence and potential cloning sites in the polylinker region between the Gal4 aa codon 147 and the Gro start codon are shown at the bottom (the vector and complete DNA sequence of pVLf:Gal4-Gro are available from the authors upon request). 
(Stratagene, La Jolla, CA, USA) directed polymerase chain reaction (PCR) mutagenesis using the plasmid pActGal4-Gro (3) as DNA template and the following pair of primers: 5'-AAGCCTGCGGCCGCCATGGACTACAAGGACGACGATGACAAGATGAAGCTACTGTCTTCTATC-3' and 5'-TCGCTTGCGGCCGCGTTGCTACTGCCGCCTTTCTGC-3'. The initiation ATG codon of FLAG epitope was in a Kozak consensus context 5'-GCCATGG-3' to maximize the efficiency of translation in eukaryotic cells (6). This PCR product was digested with the restriction enzyme NotI, purified by gel electrophoresis and cloned into the NotI site of the baculovirus transfer vector pVL1392 (PharMingen, San Diego, CA, USA). The sequence of the vector was verified by DNA sequencing. As Figure 1 shows, multiple cloning sites located in the polylinker regions allow the easy excision of the Gro cDNA insert and the insertion of other protein-coding genes of interest to generate in-frame fusion with Gal4 DBD. Thus, pVLf:Gal4-Gro provides a general template to prepare DNA constructs for baculovirus expression of Gal4-fusion proteins in insect cells.

To generate the recombinant baculovirus expressing FLAG-tagged Gal4Gro, we co-transfected pVLf:Gal4-Gro and BaculoGold ${ }^{\circledR}$ DNA (PharMingen) into Sf9 insect cells using the BaculoGold Transfection Kit and protocols (PharMingen). The BaculoGold DNA has the distinct advantage that recombination with the transfer vector is required to produce viable virus particles. Thus, tedious plaque purification is unnecessary. The cell media was therefore collected five days posttransfection and directly used for virus amplification without further purification. Five rounds of amplification according to the procedure described by PharMingen usually gave a virus titer of $2-3 \times$ $108 / \mathrm{mL}$ as determined by plaque assays. To produce recombinant proteins, we then infected a monolayer of about $10^{9} \mathrm{Sf} 9$ cells (at $60 \%$ confluence) with the amplified virus stock at a multiplicity of infection (MOI) of 5. We generally observed a higher level of expression with monolayers than with cells cultured in spinner bottles (data not shown). At $40 \mathrm{~h}$ post-infection, Sf9 cells were harvested, and nuclear extracts were prepared as follows.

After a brief rinse with phosphatebuffered saline (PBS) $\mathrm{pH} \mathrm{7.4,} \mathrm{the} \mathrm{cell}$ pellet was resuspended in $25 \mathrm{~mL}$ (5 packed-cell volumes) of hypotonic buffer $\mathrm{H}$ [10 mM HEPES, pH 7.9, 10 $\mathrm{mM} \mathrm{KCl}, 1.5 \mathrm{mM} \mathrm{MgCl} 2,1 \mathrm{mM}$ dithiothreitol (DTT), $1 \mathrm{mM}$ phenylmethyl sulfonyl fluoride (PMSF), $2 \mathrm{mM}$ benzamidine, $10 \mu \mathrm{g} / \mathrm{mL}$ leupeptin, $10 \mu \mathrm{g} / \mathrm{mL}$ pepstatin A, $2 \mu \mathrm{g} / \mathrm{mL}$ aprotinin, 200 $\mu \mathrm{g} / \mathrm{mL}$ sodium metabisulfite] and incubated on ice for $30 \mathrm{~min}$. Cells were then lysed with a dounce homogenizer (B pestle, 20 strokes) on ice, and nuclei were pelleted by centrifugation at $2000 \times g$ for $15 \mathrm{~min}$. Nuclei were resus-

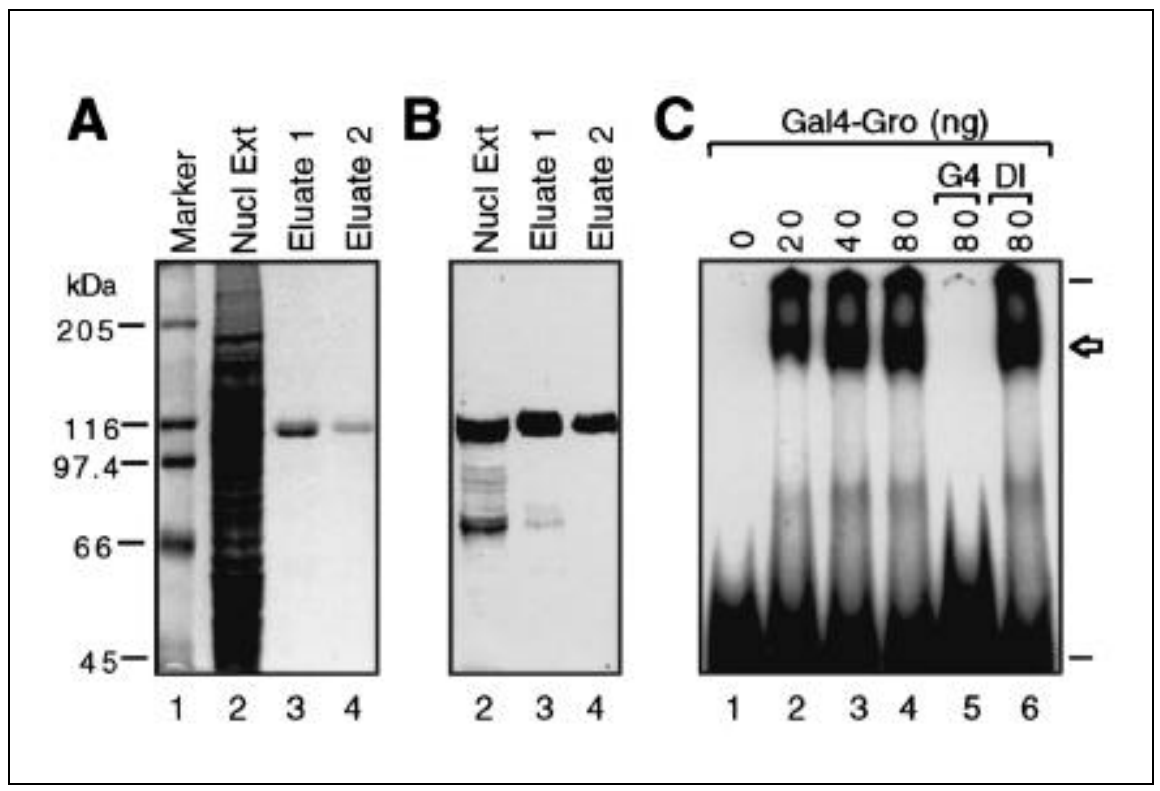

Figure 2. Functional analysis of immunoaffinity-purified Gal4-Gro fusion protein. (A) Expression and purification of Gal4-Gro fusion protein (see text for detail). A Coomassie Blue-stained 6\% SDSPAGE gel is shown: lane 1, protein mass markers with sizes in $\mathrm{kDa}$ indicated on the left; lane 2, $10 \mu \mathrm{L}$ of nuclear extract (Nucl Ext) prepared from Sf9 cells infected with the baculovirus expressing FLAGtagged Gal4-Gro; lanes 3 and 4, $10 \mu \mathrm{L}$ of immunoaffinity-purified Gal4-Gro from two consecutive elutions. (B) Immunoblotting analysis of purified Gal4-Gro with anti-Gal4 polyclonal antibody. Each lane was loaded with the same material described in Panel A. (C) EMSA of purified Gal4-Gro. Approximately $5 \mathrm{fmol}$ of ${ }^{32} \mathrm{P}$-labeled ds oligonucleotide containing a Gal4 binding site were used in each assay: lane 1 , probe alone; lanes 2-4, probe incubated with 20,40 or $80 \mathrm{ng}$ of purified Gal4-Gro, respectively; lane 5, probe with $80 \mathrm{ng}$ of Gal4-Gro and 100-fold molar excess of unlabeled oligonucleotides containing a Gal4 binding site (G4); lane 6, probe with $80 \mathrm{ng}$ of Gal4-Gro and 100-fold molar excess of unlabeled oligonucleotide containing a Dorsal binding site (Dl). Lines mark the wells and free probes, while an arrow indicates the retarded DNA-protein complex. 


\section{Benchmarks}

pended in $10 \mathrm{~mL}$ of Buffer $2(25 \mathrm{mM}$ HEPES, pH 7.6, $0.45 \mathrm{M} \mathrm{NaCl}, 5 \mathrm{mM}$ $\mathrm{MgCl}_{2}, 20 \%$ glycerol, $1 \mathrm{mM}$ EDTA, 1 mM DTT, 1 mM PMSF, 2 mM benzamidine, $10 \mu \mathrm{g} / \mathrm{mL}$ leupeptin, $10 \mu \mathrm{g} / \mathrm{mL}$ pepstatin A, $2 \mu \mathrm{g} / \mathrm{mL}$ aprotinin, 200 $\mu \mathrm{g} / \mathrm{mL}$ sodium metabisulfite). Nuclear proteins were extracted by gentle rocking at $4^{\circ} \mathrm{C}$ for $1 \mathrm{~h}$. The nuclear extracts were cleared by ultracentrifugation at $100000 \times g$ for $1 \mathrm{~h}$ and subsequently incubated overnight at $4^{\circ} \mathrm{C}$ with $0.5 \mathrm{~mL}$ of FLAG M2 Affinity Gel (Scientific Imaging Systems [Eastman Kodak], New Haven, CT, USA) that had been pre-equilibrated with Buffer 2.

We further batch-purified the FLAG-tagged Gal4-Gro. M2 affinity beads were first washed $3 \times$ with $10 \mathrm{~mL}$ of Buffer 2, and then $6 \times$ with $10 \mathrm{~mL}$ of a buffer similar to Buffer 2 but containing $1 \mathrm{M} \mathrm{NaCl}, 1 \%$ 3-[(3-cholamidopropyl)dimethylammonio]-1-propane-sulfonate (CHAPS), and 1\% Nonidet ${ }^{\circledR}$ P-40 (NP40). After washing three more times with $10 \mathrm{~mL}$ of Buffer 2, bound FLAG-tagged Gal4-Gro fusion proteins were eluted $2 \times$ by incubating the beads with $0.5 \mathrm{~mL}$ of Buffer 2 containing 2 $\mathrm{mg} / \mathrm{mL}$ of synthetic FLAG peptide (crude; Quality Controlled Biochemicals, Hopkinton, MA, USA) and $0.05 \%$ NP40 at room temperature for $1 \mathrm{~h}$. The supernatants were collected and finally dialyzed into Buffer D $(20 \mathrm{mM}$ HEPES, pH 7.9, $50 \mathrm{mM} \mathrm{NaCl}, 10 \%$ glycerol, $1 \mathrm{mM}$ EDTA, $1 \mathrm{mM}$ DTT, 1 $\mathrm{mM}$ PMSF and $1 \mathrm{mM}$ sodium metabisulfite). After dialysis, $10 \mu \mathrm{L}$ of each eluted fraction were analyzed by sodium dodecyl sulfate polyacrylamide gel electrophoresis (SDS-PAGE), and a major $110-\mathrm{kDa}$ protein band (more than $95 \%$ pure) was visualized by Coomassie ${ }^{\circledR}$ Blue staining (Figure 2A). The size of this band is in good agreement with the predicted apparent molecular mass of FLAG-tagged Gal4-Gro $(108 \mathrm{kDa})$. The identity of purified product was further confirmed by immunoblotting analyses with anti-Gal4 DBD polyclonal (Santa Cruz Biotechnology, Santa Cruz, CA, USA; shown in Figure 2B), anti-FLAG M2 monoclonal (Scientific Imaging Systems) (data not shown) and anti-Gro monoclonal antibodies (data not shown). Using Bradford protein assays (Bio-Rad, Hercules, CA, USA), we estimate a yield of $0.1-0.2 \mathrm{mg}$ of pure Gal4-Gro from $10^{9}$ infected Sf9 cells.

Purified Gal4-Gro was next analyzed by EMSA to ensure that the purified fusion was functionally intact and that it had the same DNA binding specificity as Gal4. Using the procedure described previously (1), a ${ }^{32} \mathrm{P}$ labeled, double-stranded (ds) oligonucleotide (5'-CGCTCGGAGGACA-GTACTCCGCTCG-3') bearing the consensus binding site (underlined) for Gal4 was incubated with various amounts (20-80 ng) of purified Gal4Gro (Figure 2C, lanes 2-4). A major band corresponding to the retarded DNA-protein complex (Figure 2C, arrow) was observed. The specificity of the DNA binding was demonstrated by competition experiments with unlabeled specific and nonspecific ds oligonucleotides. Figure $2 \mathrm{C}$ shows that addition of a 100-fold molar excess of unlabeled Gal4-binding, ds oligonucleotides completely abolished the radiolabeled complex (lane 5). In contrast, the addition of same amount of an unrelated, unlabeled ds oligonucleotide (5'-TGATTGGGTTTCTCCCAGTTA$\left.3^{\prime}\right)$ bearing a Dorsal binding site (underlined) had no effect on binding to the radiolabeled probe (lane 6). Using this highly purified Gal4-Gro fusion protein, we are currently attempting to reconstitute Gro-mediated repression in a cell-free transcription system.

In summary, we describe a novel baculovirus transfer vector allowing highlevel expression of FLAG-tagged Gal4 DBD fusion proteins in insect cells that provide a eukaryotic environment for appropriate posttranslational modifications and protein folding. This vector is especially useful for expression and purification of large Gal4-fusion proteins. Over-expressed Gal4-fusion proteins can be easily purified to near homogeneity in one step from the nuclear extracts of infected insect cells by a described immunoaffinity-purification procedure. In addition, immunoaffinity-purified, Gal4-fusion proteins can be recognized by commercially available anti-Gal4 DBD and anti-FLAG antibodies and can also specifically bind to DNA bearing Gal4-binding sites. The same immunoaffinity purification procedure has also been proven to be extremely successful in purifying many other transcription factors (data not shown). Furthermore, highly purified FLAG-tagged Gal4 fusion or non-fusion proteins can be re-immobilized on the FLAG affinity beads and used in protein-protein interaction assays or as an affinity matrix for purifying interacting proteins.

\section{REFERENCES}

1.Carey, M., H. Kakidani, J. Leatherwood, F. Mostashari and M. Ptashne. 1989. An amino-terminal fragment of GAL4 binds DNA as a dimer. J. Mol. Biol. 209:423-432.

2.Fisher, A.L. and M. Caudy. 1998. Groucho proteins: transcriptional corepressors for specific subsets of DNA-binding transcription factors in vertebrates and invertebrates. Genes Dev. 12:1931-1940.

3.Fisher, A.L., S. Ohsako and M. Caudy. 1996. The WRPW motif of the hairy-related basic helix-loop-helix repressor proteins acts as a 4-amino-acid transcription repression and protein-protein interaction domain. Mol. Cell. Biol. 16:2670-2677.

4.Kadonaga, J.T. 1998. Eukaryotic transcription: an interlaced network of transcription factors and chromatin-modifying machines. Cell 92:307-313.

5.Koh, S.S., A.Z. Ansari, M. Ptashne and R.A. Young. 1998. An activator target in the RNA polymerase II holoenzyme. Mol. Cell 1:895-904.

6.Kozak, M. 1987. An analysis of $5^{\prime}$-noncoding sequences from 699 vertebrate messenger RNAs. Nucleic Acids Res. 15:8125-8148.

7.Lin, Y.S., M.F. Carey, M. Ptashne and M.R. Green. 1988. GAL4 derivatives function alone and synergistically with mammalian activators in vitro. Cell 54:659-664.

8.Sadowski, I. and M. Ptashne. 1989. A vector for expressing GAL4 (1-147) fusions in mammalian cells. Nucleic Acids Res. 17:7539.

9.Schmitz, M.L. and P.A. Baeuerle. 1994. A vector, pHisGal, allowing bacterial production of proteins fused to a hexahistidine-tagged Gal4 DNA-binding domain. BioTechniques 17:714-718.

10.Schmitz, M.L. and P.A. Baeuerle. 1997. Bacterial expression, purification, and potential use of His-tagged GAL4 fusion proteins. Methods Mol. Biol. 63:129-137.

11.Witzgall, R., E. O'Leary and J.V. Bonventre. 1994. A mammalian expression vector for the expression of GAL4 fusion proteins with an epitope tag and histidine tail. Anal. Biochem. 223:291-298.

FLAG is a registered trademark of Immunex Corporation. We thank M. Caudy for kindly providing the plasmid pActGal4-Gro, $J$. Zwicker and R. Tjian for very useful advice on FLAG immunoaffinity purification, and J. Shirokawa for technical assistance with insect cell culture. This work was supported by National Institutes of Health 
Grant No. GM44522 to A.J.C. Address correspondence to Dr. Albert J. Courey, Department of Chemistry and Biochemistry, University of California, Los Angeles, CA 90095-1569, USA. Internet: courey@chem. ucla.edu

Received 15 October 1998; accepted 22 January 1999.

\section{Guoqing Chen and Albert J.} Courey

University of California, Los Angeles

Los Angeles, CA, USA

\section{Generation of Epitope- Tagged Proteins by Inverse PCR Mutagenesis}

BioTechniques 26:814-816 (May 1999)

The polymerase chain reaction (PCR) has been extensively used for the mutation of DNA sequences $(1-5,7,8)$. Many variations of the protocol have been implemented, but most involve a first step in which PCR is used to modify the molecule, and a second step in which the new sequence is subcloned into a vector. A new method, named inverse PCR mutagenesis (IPCRM) has been shown to be an efficient and rapid way to introduce point mutations into DNA sequences cloned in plasmid vectors without the requirement of a subcloning step $(2,3,7,8)$. The technique consists of a PCR amplification of the vector using a set of two adjacent nonoverlapping oligonucleotides, one of which encodes the desired mutation. Since the PCR product can be longer than $10 \mathrm{~kb}$, the use of $P f u$ DNA polymerase is recommended, not just because of its high fidelity but also because it generates blunt-ended PCR products, eliminating the need for end polishing. The PCR product is then ligated, treated with $D p n I$ to digest methylated contaminating parental plasmid

\section{Table 1. Modified IPCRM Protoco}

1. Both primers $(50 \mathrm{pmol} / \mu \mathrm{L}$ each) were phosphorylated in the same tube for $30 \mathrm{~min}$ at $37^{\circ} \mathrm{C}$ using T4 Polynucleotide Kinase (Amersham Pharmacia Biotech, Piscataway, NJ, USA).

2. The PCR mixture $(50 \mu \mathrm{L})$ was prepared with $50 \mathrm{pmol} / \mu \mathrm{L}$ of each phosphorylated primer, $200 \mathrm{mM}$ of each dNTP, $1.25 \mathrm{U}$ of Pfu DNA Polymerase, $20 \mathrm{ng}$ of template plasmid and $5 \mu \mathrm{L}$ of Pfu Reaction Buffer (Stratagene, La Jolla, CA, USA).

3. Following an initial $94^{\circ} \mathrm{C}$ denaturing step for $4 \mathrm{~min}$, the reaction was cycled $16 \times$ through $94^{\circ} \mathrm{C}$ for $30 \mathrm{~s}, 60^{\circ} \mathrm{C}$ for $30 \mathrm{~s}$ and $72^{\circ} \mathrm{C}$ for $20 \mathrm{~min}(2.5 \mathrm{~min} / \mathrm{kb}$ of template). The reaction was terminated by a final extension step at $72^{\circ} \mathrm{C}$ for $25 \mathrm{~min}$.

4. The amplified product was confirmed by running $5 \mu \mathrm{L}$ of the reaction in $1 \%$ agarose gel.

5. The remaining sample was purified by GENECLEAN ${ }^{\circledR}$ Kit (BIO 101, Vista, CA, USA), resuspended in $7.5 \mu \mathrm{L}$ of $10 \mathrm{mM}$ Tris- $\mathrm{HCl}, \mathrm{pH} 8.5$, and mixed with $1 \mu \mathrm{L}$ ligation buffer, $1 \mu \mathrm{L} 50 \mathrm{mM}$ dithiothreitol (DTT) and $2 \mathrm{U}$ T4 Ligase from a PRIME EFFICIENCYтм DNA Ligation Kit (Eppendorf Five Prime, Boulder, CO, USA). The ligation reaction was run for $40 \mathrm{~min}$ at room temperature, followed by heat-inactivation for $10 \mathrm{~min}$ at $65^{\circ} \mathrm{C}$.

6. After ligation, $8 \mu \mathrm{L}$ of water and $2 \mu \mathrm{L}$ of $D p n$ l (New England Biolabs) were added to the sample and incubated for $4 \mathrm{~h}$ at $37^{\circ} \mathrm{C}$.

7. One microliter of the final reaction was used to transform $50 \mu \mathrm{L}$ of Epicurean coli ${ }^{\circledR}$ XL2-Blue cells (Stratagene) according to the company protocol.

8. After overnight incubation, ten colonies were selected and grown for plasmid minipreps.

and subsequently introduced into competent cells through transformation. IPCRM is a suitable method to produce substitution and deletion mutations in sequences already cloned into a specific vector (3).

We have extended the IPCRM method to permit insertion of epitope tags into a target protein of interest. Routinely, tagged proteins are generated by cloning the coding sequence into a multiple cloning site of a vector that already contains the epitope sequence (6). Changing the epitope or even its location with respect to the target protein requires either the use of new vectors or extensive cloning procedures. Using IPCRM, it is possible to insert short peptide sequences anywhere within the vector, requiring only a pair of primers.

To illustrate the procedure, we have fused the $F_{L A G}{ }^{\circledR}$ epitope sequence

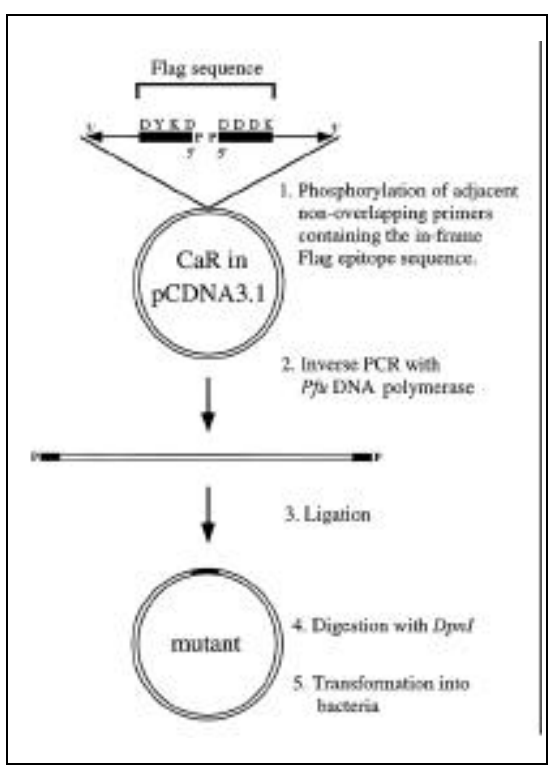

Figure 1. Overview of Modified IPCRM Protocol. 